\title{
MEMBANGUN FRAMEWORK REPOSITORY SOURCE CODE ALGORITMA KOMPUTER PADA PLATFORM WEB
}

\author{
Amrullah'), Mutasar ${ }^{2)}$ \\ 1) Jurusan Informatika, Fakultas Ilmu Komputer, Universitas Islam Kebangsaan Indonesia \\ 2) Jurusan Informatika, Fakultas Ilmu Komputer, Universitas Islam Kebangsaan Indonesia \\ e-mail:amstmik9@gmail.com
}

\begin{abstract}
[Building a Computer Algorithm Source Code Repository Framework on a Web Platform] In the era of the Industrial Revolution 4.0 programmers were presented with a CMS platform, a Web builder that accelerated the creation of programs such as responsive / dynamic create templates, CRUD and graphics but there is no framework for building source code on a web platform that breaks the process flow of an algorithm so that it will help programmers / researchers in solve arithmetic / logical process problems in an algorithm / method if implemented into the web platform HTML, PHP, CSS source code. The urgency of this problem must be a repository system that provides source code for computer algorithms including (expert systems, data mining, decision systems, artificial intelligence, cryptography / computer security, information systems, searching, image processing). The existence of this repository will make it easy to produce source code algorithms / computer methods that can be used as, modify, combine, comparation, example, trying, testing, implementation, so that it will be easy to complete research programs and help accelerate the rate of programmer / researcher skills in college high.
\end{abstract}

\section{Keywords : Framework, Repository, Algoritma, Source Code, Platform Web}

\begin{abstract}
Abstrak
Era Revolusi Industri 4.0 programmer dihadirkan platform CMS, Web builder yang mempercepat pembuatan program seperti create templete responsive/dinamis, CRUD dan grafik namun belum adanya framework untuk membangun source code pada platform web yang memecahkan alur proses pada sebuah algoritma sehingga akan membantu programmer/peneliti dalam menyelesaikan masalah aritmatika/logical proses pada sebuah algoritma/metode jika di-implementasikan kedalam source code platform web HTML, PHP, CSS. Urgensi permasalahan ini harus adanya sistem repository yang menyediakan source code algoritma komputer meliputi (expert system, data mining, decision system, artificial intelligence, kriptografi/security computer, system information, searching, image processing). Adanya repository ini akan memberikan kemudahan dalam menghasilkan source code algoritma/metode komputer untuk dapat digunakan sebagai, modify,combine, comparation, example, trying, testing, implementation, sehingga akan mudah dalam penyelesaian program penelitian dan membantu mempercepat laju skill programmer/peneliti di perguruan tinggi.
\end{abstract}

Kata Kunci: Framework, Repository, Algoritma, Source Code, Platform Web

\section{Pendahuluan}

Era revolusi industri 4.0 sangat menggeser dan menggantikan peran berbagai aspek bidang baik kerja maupun pendidikan selain kehandalan dan kepraktisan, kemudahan serta aksessibiliti yang tidak terbatas termasuk dalam bidang pemrograman komputer pada bidang web (Irsyada, Dardiri, \& Sugandi, 2018). Sangat banyak bermunculan framework pada platform web mulai dari CMS, Website Builder maupun yang standard HTML, CSS. Munculnya framework web sangat bermanfaat untuk membuat sebuah website secepat dan semurah penyajian secangkir kopi misalnya CI, Laravel, Jomla, Wordpres, YII Framework, Hugo, WIX, dimana framework tersebut menawarkan generator templete, CRUD builder, sehingga sangat langsung bisa siap untuk membuat sebuah website (Ang, 2018; Das \& Saikia, 2016; Priefer, Kneisel, \& Strüber, 2017; Rahardja, Aini, \& Thalia, 2018).

Namun ada permasalahan lain yang dihadapi oleh programmer baik level awal maupun expert, dan juga mahasiswa tingkat akhir dalam menyelesaikan penelitian dimana harus memecahkan masalah algoritma dengan bahasa computer, tidak sedikit yang terkendala pada penyelesaian algoritma, misalnya pada penyelesaian 
penelitian system pakar, neural network, artificial intelligence, image processing, decision support, maupun data mining (Sukarsa, 2019).

Berlatar masalah demikian memungkinkan urgensi dari masalah ini adalah belum tersedianya framework yang membantu dunia pendidikan tinggi untuk lebih memudahkan peneliti ditingkat mahasiswa dalam menyelesaikan masalah penelitian pada algoritma computer. Oleh demikian hadirnya repository source code algoritma komputer akan memberikan kemudahan dalam membangun website (builder web berdasarkan jenis algoritma) sehingga peneliti akan mudah mendapatkan source code HTML, PHP, CSS + Algoritma (metode: Fuzzy, Ant System, Decission Tree, C5. C4.5, CBR, Forward \& Backward Chaining, Genetika, Swarm, Topsis, Promethe, AHP,SAW, ACO, Moora, Tabu search, DSA, RSA, DH, ECC, Quantum, C 4.5, K-Means, Support Vector Machines, Apriori, Expectation Maximisation Algorithm, PageRank,k-Nearest Neighbors, Naive Bayes,WP, Certainty Factor, Dempster Shafer, B/C Ratio, IRR, NPV, FMADM, dsb, sehingga akan mudah menyelesaikan penelitian (Mu, Yang, Chen, \& Wang, 2020; PM, Batubulan, \& Fauziyyatul'Iffah, 2019; Sari, Khatimi, \& Rusiana, 2020; Widhianto, Supianto, \& Setiawan).

Untuk menjaga etik dari kemampuan mahasiswa terhadap penggunaan framework algoritma builder ini bukanlah hasil final untuk mendapatkan sebuah website yang siap digunakan melainkan hanya sebuah source code algoritma(metode) tertentu (ex: ant system) yang akan dihasilkan, dan ini akan memberikan wawasan kepada peneliti bagaimana algoritma tersebut menjalankan prosesnya pada source code platform web. Selanjutnya peneliti dapat menggunakan/menyelipkan/implementasi pada program web yang sedang diteliti melalui cara modify,combine, comparation, example, trying, dan testing . Dengan demikian skil mahasiswa dibidang programmer tetap akan terjaga dan membangun rasa percaya diri jika program yang dibuat telah di uji kebenarannya pada framework "Framework Repository Source Code Algoritma Komputer".

\section{Metode}

Metode penelitian dalam perancangan repository framework source code algoritma menggunakan metode analisis dan perancangan prototype serta pengujian dan implementasi generator sejauh mana mampu membangkitkan source code open source yang baik statis maupun dinamis.

Untuk menghasilkan source code algoritma computer, perancangan framework adanya customize dari pengguna/user dengan menentukan variable, alternative, rule, hipotesa yang berhubungan dengan algoritma sesuai kebutuhan variable pada jenis sebuah algoritma. Hal ini disebut system customize yang tentukan akan dibentuk pula query database karena indicator/alternative, variable dari sebuah algoritma akan diproses dan disimpan dalam database dengan model PDO (Program Data Object). Alur proses rancangan seperti pada gambar berikut :

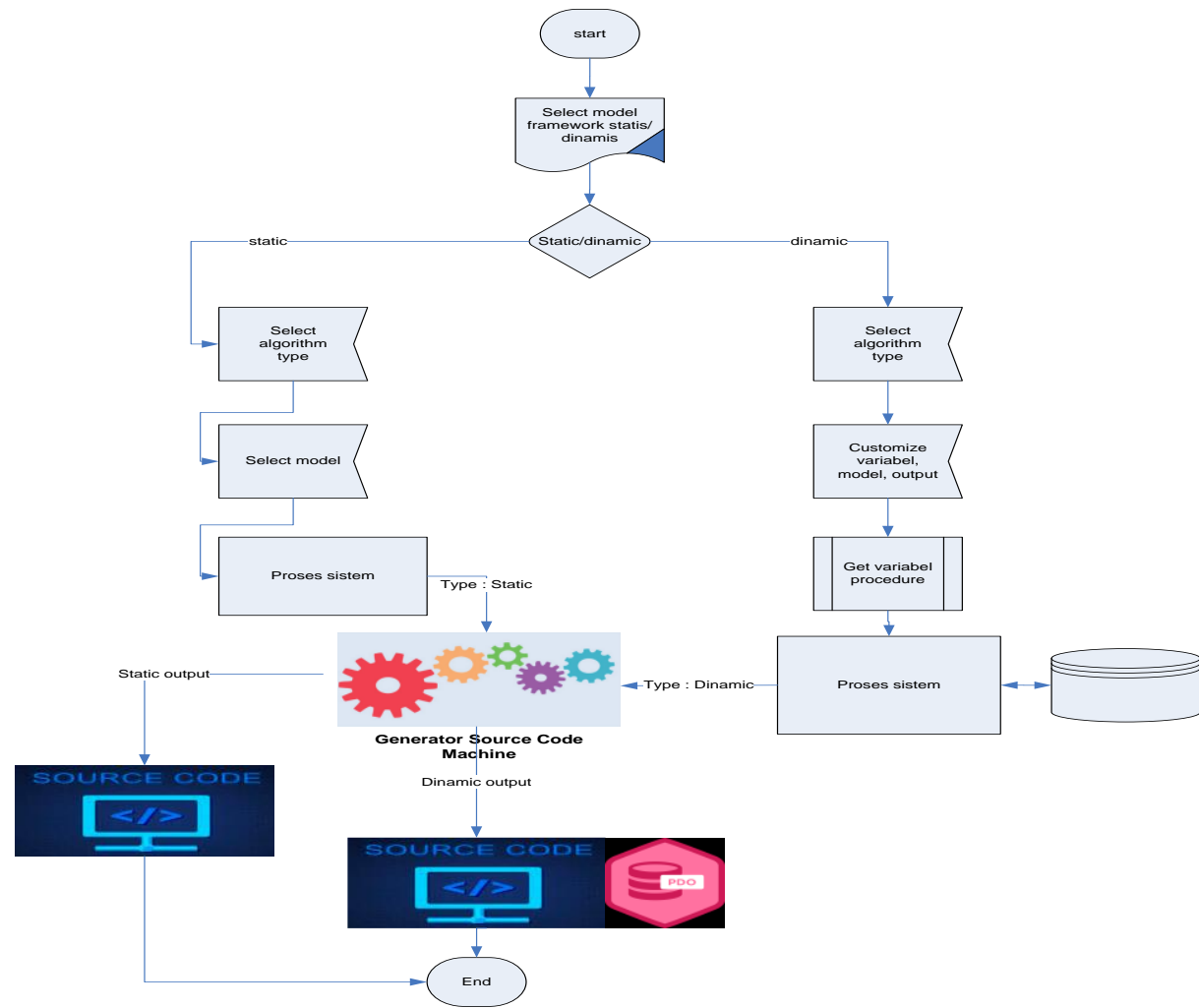

Gambar 1. Diagram Alur Proses Sistem. 


\section{Hasil dan Pembahasan}

Framework Code Generator menghasilkan dua versi output yaitu, output source code secara statis dan output source code secara dinamis. Hasil output statis tidak menggunakan database yang dapat di custome. Berikut tampilan utama dari sistem repository source code algoritma dapat dilihat pada gambar berikut:

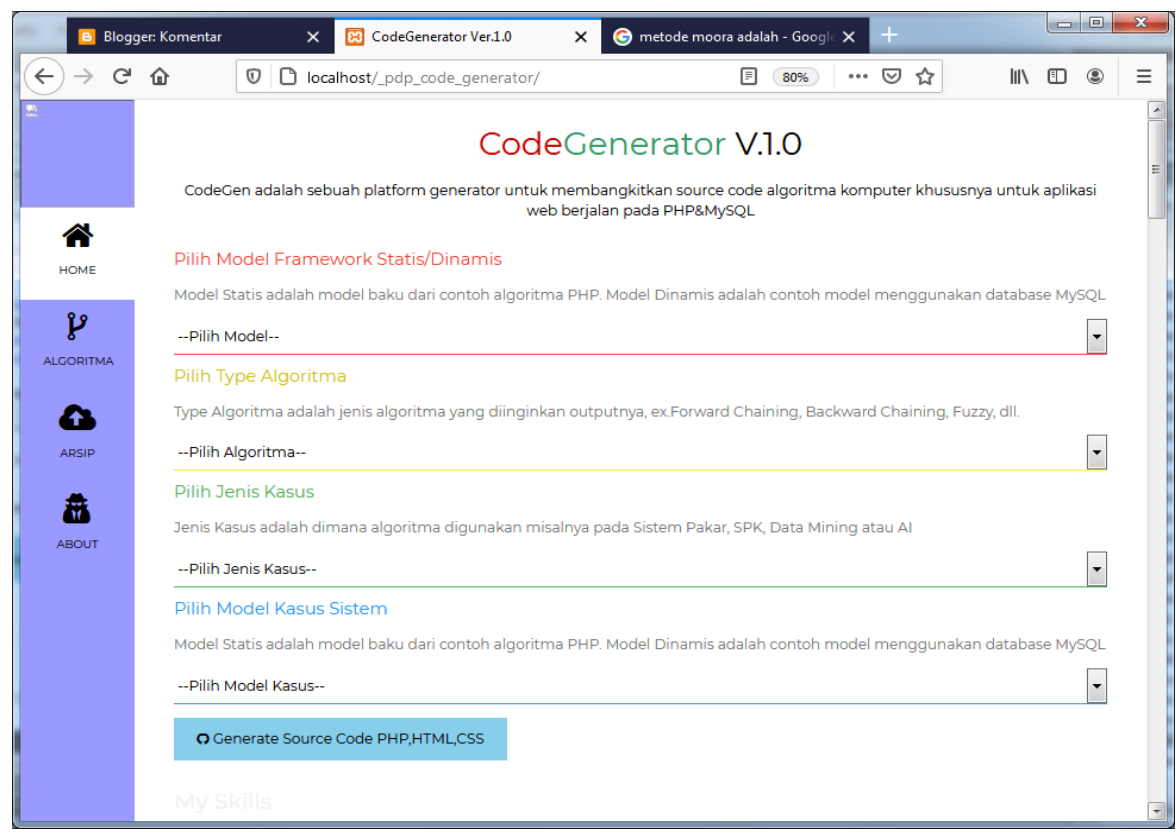

Gambar 2. Tampilan Utama Sistem Code Generator (CodeGenV1.0)

Untuk menggunakan sistem guna menghasilkan/generate source code algoritma maka user harus menentukan empat pilihan. Pertama user pilih jenis framework statis atau dinamis, ke-dua user memilih type algoritma seperti forward chaining, certainty factor dan sebagainya, ke-tiga user memilih jenis kasus contohnya sistem pakar efisiensi tanaman hidroponik, dan ke-empat : user memilih model sistem yang akan diterapkan seperti sistem pakar, data mining, SPK , ataupun Kecerdasan buatan (AI). Setelah semua terpilih maka lakukan generate algoritma guna menghasilkan source code algoritma berbasis PHP,HTML,CSS dengan menekan tombol “Generate Source Code PHP,HTML,CSS" maka sistem akan memproses hingga menghasilkan sebuah framework dalam bentuk source code.Dapat dilihat seperti pada gambar berikut :

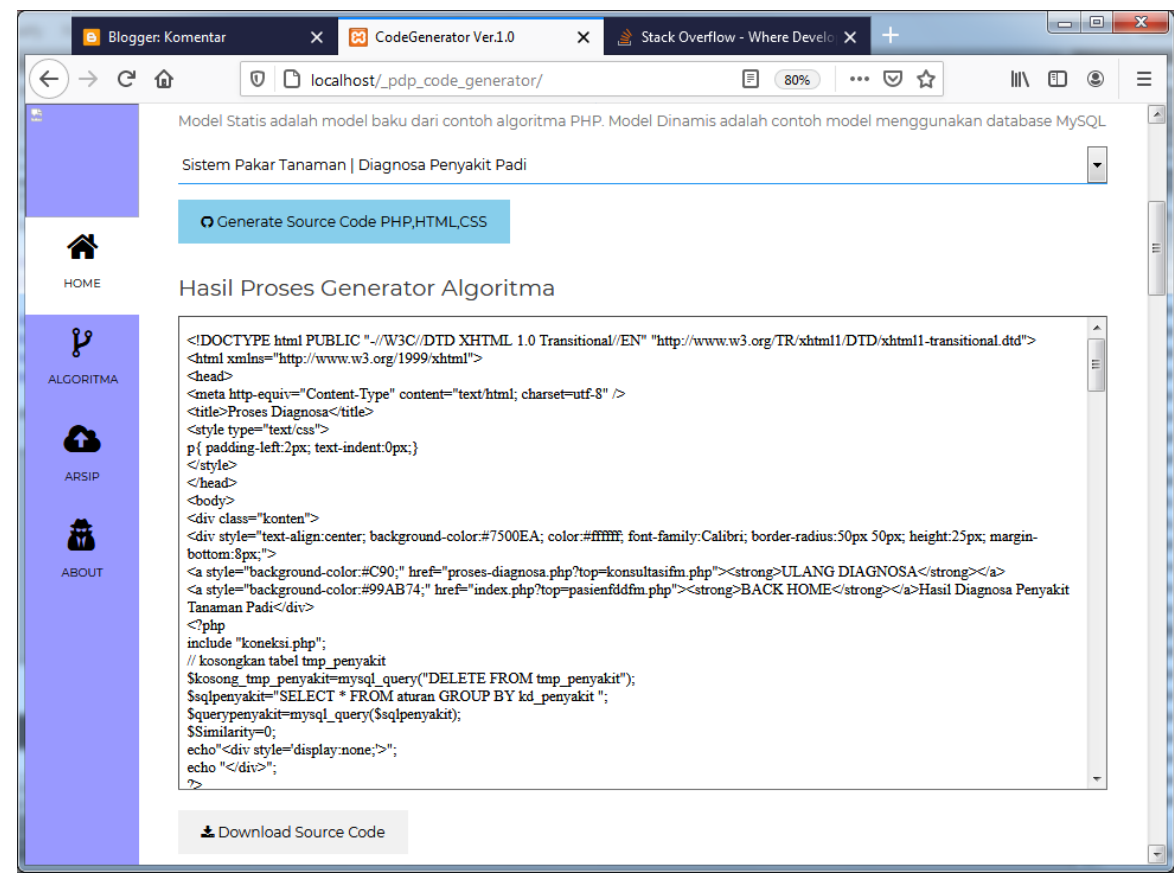

Gambar 3. Tampilan Hasil Proses Generator, Source Code Algoritma Statis 
Selanjutnya menguji Framework pada sistem algoritma dinamis.Algoritma dinamis ini terdapat database yang dapat dicustome, dan menghasilkan database MySQL dalam bentuk ektensi *.sql sehingga mudah untuk di distribusikan/import kedalam database engine. Berikut tampilan hasil proses source code algoritma dinamis dapat dilihat pada gambar berikut:

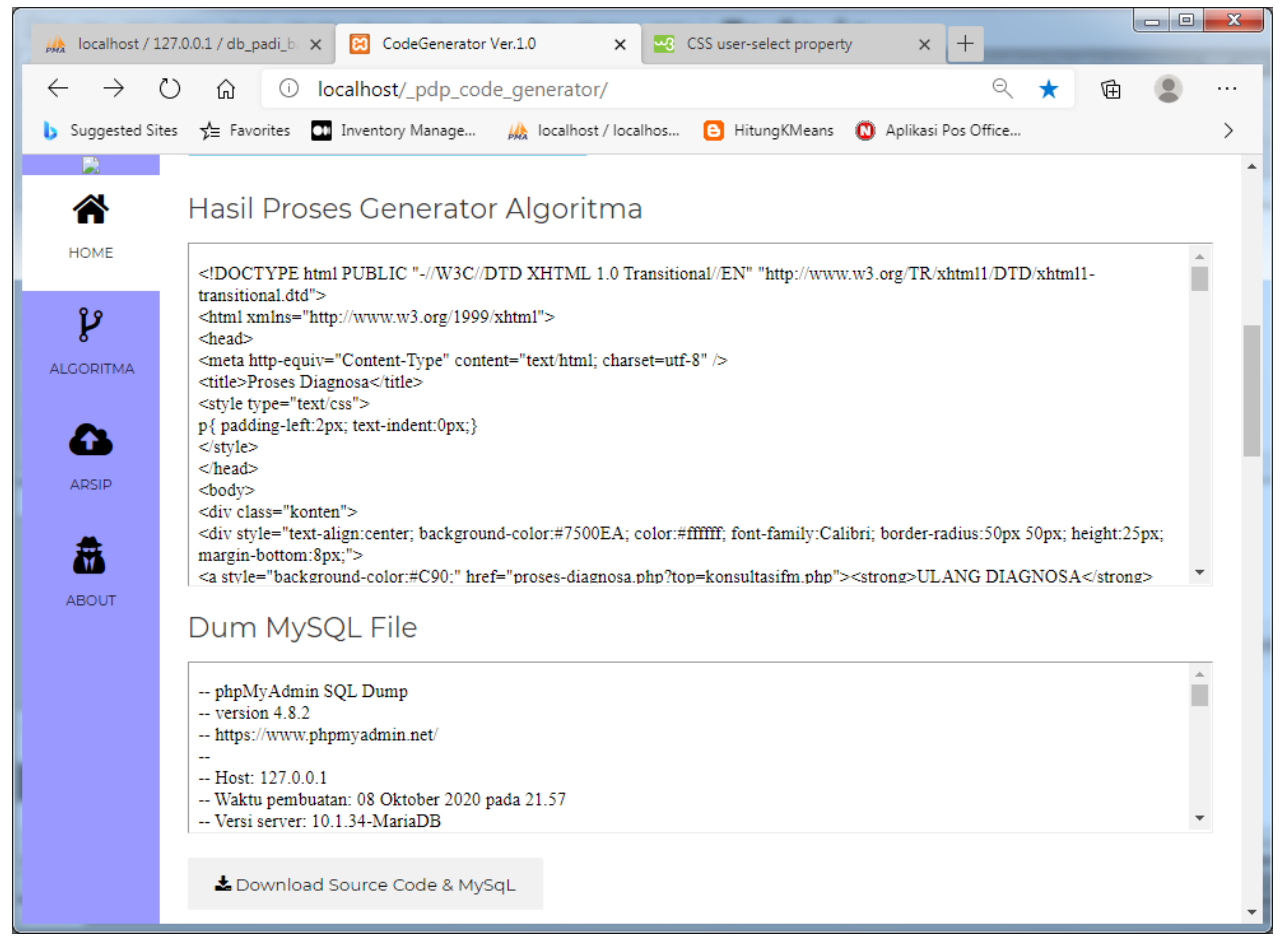

Gambar 4. Tampilan Hasil Proses Generator, Source Code Algoritam Dinamis

Secara default hasil dari source code algoritma menghasilkan file utama yaitu index.php dan disertai dengan file pendukung yang saling berelasi misalnya page untuk menginput variabel, penginputan alternative/case, serta pengesetan rule dari sebuah algoritma. Hal ini berlaku untuk source code statis dan dinamis.

\section{Kesimpulan}

Berdasarkan hasil perancangan dan pengujian dapat disimpulkan bahwa Framework repository algoritma komputer dapat menghasilkan aplikasi/sistem dalam bentuk statis dan dinamis serta dapat men-generate dum database mysql sehingga dapat digunakan untuk mendukunga program. Hasil dari pengujian sistem dapat mengenerate algoritma dalam bentuk source code kedalam Bahasa pemrograman web PHP,HTML,CSS dan MySQL database.

Saran dalam penelitian ini untuk pengembangan lebih lanjut maka dapat dikembangkan model "Developer" dengan menambah fitur API yang memungkin programmer lain untuk bekontribusi dalam pengembangan Framwork algoritma web serta memperkaya repository source code algoritma.

\section{Daftar Pustaka}

Ang, R. J. (2018). WordPress as a platform for nursing informatics. Canadian Journal of Nursing Informatics, $13(3 / 4)$.

Das, R., \& Saikia, L. P. (2016). Comparison of Procedural PHP with Codeigniter and Laravel Framework. International Journal of Current Trends in Engineering \& Research, 2(6), 42-48.

Irsyada, R., Dardiri, A., \& Sugandi, R. M. (2018). Kontribusi Minat Berwirausaha dan Self Efficacy terhadap Kesiapan Berwirausaha di Era Revolusi Industri 4.0 Mahasiswa Teknik Informatika se-Malang. Jurnal Pendidikan: Teori, Penelitian, dan Pengembangan, 3(7), 945-954.

Mu, C., Yang, M., Chen, Z., \& Wang, B. (2020). Research on RSA Padding Identification Method in IoT Firmwares. Paper presented at the Journal of Physics: Conference Series.

PM, D. K., Batubulan, K. S., \& Fauziyyatul'Iffah, N. (2019). Implementasi Metode AHP dan TOPSIS untuk Rekomendasi Wisata Kota Batu. Paper presented at the Seminar Informatika Aplikatif Polinema. 
Priefer, D., Kneisel, P., \& Strüber, D. (2017). Iterative Model-Driven Development of Software Extensions for Web Content Management Systems. Paper presented at the European Conference on Modelling Foundations and Applications.

Rahardja, U., Aini, Q., \& Thalia, M. B. (2018). Penerapan Menu Konfirmasi Pembayaran Online Berbasis Yii pada Perguruan Tinggi. Creative Information Technology Journal, 4(3), 174-185.

Sari, Y., Khatimi, H., \& Rusiana, N. (2020). Penentuan Jenis Batubara Berbasis Pengolahan Citra Digital Menggunakan Metode Logika Fuzzy. Jurnal Ilmu Komputer dan Bisnis, 11(2), 2396-2405.

Sukarsa, I. M. (2019). APLIKASI KONVERSI FLOWCHART KE KODE PROGRAM BAHASA PEMROGRAMAN PL/SQL MYSQL. Majalah Ilmiah Teknologi Elektro, 8(2).

Widhianto, F. P., Supianto, A. A., \& Setiawan, N. Y. Aplikasi Data Mining Untuk Memprediksi Kelulusan Mahasiswa Menggunakan Algoritme C4. 5. Jurnal Pengembangan Teknologi Informasi dan Ilmu Komputer e-ISSN, 2548, 964X. 